Check for updates

The BMJ

Cite this as: $B M / 2022 ; 376: 0450$ http://dx.doi.org/10.1136/bmi.0450 Published: 22 February 2022

\section{Poorer access to community mental health services may have led to rise in detentions}

\section{Elisabeth Mahase}

Reduced access to community mental health services during the covid pandemic may have contributed to an increase in the number of people being detained under the Mental Health Act, England's health and care regulator has warned. ${ }^{1}$

The Care Quality Commission found that in 2020-21 a total of 53239 new detentions were recorded, a 4.5\% rise on the previous year, although it said this was likely to have been an underestimate because of missing and incomplete data.

The CQC said that community services were the "key to reducing levels of detention in hospitals," because not getting the right help at the right time can lead to symptoms worsening and people needing inpatient care.

The findings came after QualityWatch, a joint programme between the Nuffield Trust and the Health Foundation, warned that the pandemic had led to an unprecedented increase in demand for mental health services from children and teenagers in England, most notably for eating disorders. ${ }^{2}$

Health leaders told the Guardian newspaper that the pandemic had seen the waiting list for specialised mental health treatment rise to 1.6 million people, with another eight million unable to get on the list despite the service being deemed potentially beneficial for them. ${ }^{3}$

For its Monitoring the Mental Health Act report the CQC carried out 682 remote reviews of wards in 2020-21, together with interviews with 1895 patients and 1111 carers. It handled 2280 complaints from patients and others who raised concerns about the Mental Health Act, and its SOAD (second opinion appointed doctor) service reviewed the treatment plans of 14146 patients, resulting in changes to $30 \%$ of 1030 treatment plans for medication of detained patients who were refusing consent.

\section{Inequalities persist}

The report highlighted "longstanding inequalities," with black or black British people being more than four times as likely as white people to be detained. Additionally, Black or Black British people were found to have longer periods of detention and higher numbers repeated admissions than white people and were more likely to be made subject to police holding powers under the Mental Health Act.

The report found detention rates in economically deprived areas to be "worryingly high," being more than three and a half times as high as in the least deprived areas.

The CQC has called for more reliable local and national data to identify inequalities in care and to measure progress towards reducing these inequalities. "We are keen to see the rollout of the patient and carers race equalities framework, a tool to help mental health trusts work with black and minority ethnic communities to achieve practical change," the report said.

\section{Staff under pressure}

The regulator also found high levels of anxiety, stress, and burnout in the workforce and a high proportion of job vacancies. "The negative impact of working under this sustained pressure poses a challenge to the safe, effective and caring management of inpatient services and to the delivery of care in a way that maintains people's human rights," the report warned.

Jemima Burnage, the CQC's deputy chief inspector and lead for mental health, said, "The pandemic has placed unprecedented pressure on all health and social care services, the people using them, and staff working in them. Despite strains on services, we have seen many examples of good practice and the dedication of staff. However, the workforce is exhausted, with high levels of vacancies potentially risking the delivery of safe, high quality care that respects human rights."

Care Quality Commission. Monitoring the Mental Health Act in 2020/21. Feb 2022. https://www.cqc.org.uk/sites/default/files/20210127_mhareport_printer.pdf.

2 lacobucci G. Covid-19: Pandemic has disproportionately harmed children's mental health, report finds. BMJ2022;376:0430. doi: 10.1136/bmj.0430 pmid: 35181601

3 Gregory A. Millions in England face "second pandemic" of mental health issues. Guardian Feb 2022. https://www.theguardian.com/society/2022/feb/21/england-second-pandemic-mental-health-issues-nhscovid. 